\title{
Metabolic Profiles in Ovulatory and Anovulatory Primiparous Dairy Cows During the First Follicular Wave Postpartum
}

\author{
Chiho KAWASHIMA ${ }^{1}$, Minoru SAKAGUCHI ${ }^{3)}$, Takahiro SUZUKI ${ }^{4}$, \\ Yoshihiko SASAMOTO ${ }^{4)}$, Yoshiyuki TAKAHASHI ${ }^{4)}$, Motozumi MATSUI ${ }^{2)}$ and \\ Akio MIYAMOTO1)
}

${ }^{1)}$ Graduate School of Animal and Food Hygiene and ${ }^{2)}$ Department of Clinical Veterinary Science, Obihiro University of Agriculture and Veterinary Medicine, Obihiro, Hokkaido 0808555, ${ }^{3)}$ Intensive Grazing Research Team, National Agricultural Research Center for Hokkaido Region, National Agriculture and Food Research Organization, Sapporo, Hokkaido 062-8555 and ${ }^{4)}$ Graduate School of Veterinary Medicine, Hokkaido University, Sapporo, Hokkaido 0600818, Japan

\begin{abstract}
Metabolic hormones affect ovarian function in the cow. However, the relationship between metabolic factors and ovarian function is not clear in the postpartum primiparous cow because they are still growing. The aim of the present study was to investigate in detail the time-dependent profile of the metabolic hormones, metabolites, and milk yields of ovulatory and anovulatory primiparous cows during the first follicular wave postpartum. We used 16 primiparous Holstein cows and obtained blood samples for the profiles of metabolites (glucose; non-esterified fatty acid, NEFA; ketone body; total cholesterol; and aspartate aminotransferase), metabolic hormones (growth hormone, GH; insulin-like growth factor-I, IGF-1; and insulin), and progesterone every other day from 1 to 21 days postpartum. In addition, all ovaries were observed using ultrasound. Dairy milk yield was recorded during the experimental period. In all cows, the first follicular wave postpartum was observed and 6 of the cows ovulated. The plasma glucose $(\mathrm{P}<0.0001)$ and IGF-1 $(\mathrm{P}<0.001)$ concentrations were lower and the plasma NEFA $(\mathrm{P}<0.0001)$ and ketone bodies $(\mathrm{P}<0.0001)$ concentrations and daily milk yield $(\mathrm{P}<0.0001)$ were higher in the anovulatory cows compared to the ovulatory cows. However, the GH levels, which enhance lipolysis for milk production, insulin and other metabolites did not differ between the two groups. In conclusion, the present study suggests that anovulation of the dominant follicle during the first follicular wave postpartum in primiparous cows is induced by low IGF-1 levels that are similar to those of multiparous cows. In addition, anovulatory cows are likely to mobilize body fat stores for milk production more easily than ovulatory cows.
\end{abstract}

Key words: First follicular wave, Metabolic profile, Postpartum, Primiparous cow

(J. Reprod. Dev. 53: 113-120, 2007)

$t$ is generally accepted that changes in metabolic hormones affect ovarian function in cattle. Insulin and insulin-like growth factor-I

Accepted for publication: September 21, 2006

Published online: October 14, 2006

Correspondence: A. Miyamoto (e-mail: akiomiya@obihiro.ac.jp)
(IGF-1) stimulate estradiol production in the granulosa cells [1,2] and the proliferation of follicular cells $[3,4]$. IGF-1 from the liver is a factor that regulates the final maturation of the dominant follicle during the first follicular wave postpartum. That is the plasma IGF-1 levels in ovulatory cows at 
the first follicular wave postpartum are higher than those of anovulatory cows [5]. Moreover, we have previously shown that IGF-1 is an essential factor for growth of the dominant follicle, and together with insulin, it stimulates the dominant follicle to mature and reach ovulation during the first follicular wave postpartum in multiparous cows [6]. Postpartum dairy cows enter a state of serious negative energy balance at the onset of lactation [7, 8]. The metabolic condition shifts toward to catabolic metabolism that in turn causes an elevation in growth hormone $(\mathrm{GH})$ secretion and a decrease in IGF-1 and insulin [9-11]. Consequently, the serious negative energy balance that accompanies catabolic metabolism affects the onset of the first ovulation after parturition $[8,12]$.

Although the milk yield of primiparous cows is lower than that of multiparous cows [13, 14], primiparous cows are still growing. Thus, the metabolic and endocrine responses of their first lactation may be additionally compromised by the partitioning of nutrients towards somatic growth. However, in primiparous cows, the relationship between the first ovulation after parturition and metabolic status or milk yield remains unclear. Thus, the aim of the present study was to investigate in detail the time-dependent profiles of metabolic hormones, including GH, IGF-1 and insulin; metabolites, such as glucose, non-esterified fatty acid (NEFA), ketone body, total cholesterol (Tcho), and aspartate aminotransferase (AST); and milk yields of ovulatory and anovulatory primiparous cows during the first follicular wave postpartum.

\section{Materials and Methods}

All animals received humane care as outlined in the Guide for the Care and Use of Experimental Animals (Animal Care Committee, National Agricultural Research Center for Hokkaido Region).

\section{Animals}

The experiment was carried out in the National Agricultural Research Center for Hokkaido Region (Sapporo, Japan). We used 16 primiparous Holstein cows that calved between February and June 2001. All cows were housed in the same freestall barn. Throughout the experimental period, the cows were fed a diet to meet their maintenance, growth, and lactation requirements in accordance with the Japanese feeding standard (Agriculture, Forestry and Fisheries Research Council Secretariat, 1999). From May to July, the cows were pastured for 3 to $4 \mathrm{~h}$ /day, and the amount of diet was reduced to meet their nutritional requirements during this period. The cows were milked twice daily (0900 and $1900 \mathrm{~h}$ ), and milk yield was recorded daily.

\section{Sampling}

Body condition score (BCS) and body weight (BW) were measured at 1 week prepartum, on the day of parturition, and 1 week postpartum. Average BCS was assigned by two or three independent observers and recorded using a 0 to 5 scale in 0.25 intervals, with $0=$ thin and $5=$ very fat [15].

Blood samples were obtained by jugular venipuncture every other day from day 1 to day 21 postpartum. EDTA was used to prevent coagulation. Tubes were centrifuged at $3000 \mathrm{rpm}$ for 20 minutes at $4 \mathrm{C}$ and the plasma samples were kept at $-30 \mathrm{C}$ until analysis for biochemical and hormonal analyses.

\section{Ultrasound examinations of the ovary and uterus}

Ultrasound examinations were applied to monitor the first ovulation and uterine involution [16]. The ovaries of all cows were scanned 3 times / week using a real-time linear array ultrasound scanner (SSD-620; Aloka, Tokyo, Japan) equipped with a 5-MHz rectal probe (UST-580U-5; Aloka) beginning between days 6 and 8 postpartum and continuing until the first ovulation. Furthermore both uterine horns were scanned three times weekly by ultrasonography, and the maximum diameters of the stratum vasculare were measured at the base of each horn (approximately $5 \mathrm{~cm}$ anterior to the uterine body). Uterine involution was defined to be complete (days postpartum) when the diameters of both horns were $<30 \mathrm{~mm}$, and the difference in the diameters between the previously gravid and nongravid horns diminished to within $5 \mathrm{~mm}$.

\section{Measurement of P4, GH, IGF-1 and insulin}

Determination of $\mathrm{P} 4$ in plasma was performed by enzyme immunoassay (EIA) after extraction by diethyl ether as described previously [17]; the 
extraction efficiency was $93 \%$. The standard curve ranged from 0.05 to $50 \mathrm{ng} / \mathrm{ml}$, and the ED50 of the assay was $3.2 \mathrm{ng} / \mathrm{ml}$. The intra- and interassay coefficients of variation (CVs) averaged 6.7 and $7.2 \%$, respectively.

Determination for plasma GH, IGF-1, and insulin was performed by EIA using the biotinstreptavidin amplification technique.

The GH concentration was measured by the EIA technique described by Roh with slight modifications [18]. A diluted rabbit antibody to ovine GH (100 $\mu \mathrm{l}, \times 100,000$, NIDDK, AFP-0802210) was distributed in all wells of a microplate coated with anti-rabbit $\gamma$-globulin antiserum, incubated for $24 \mathrm{~h}$ at room temperature, and then the plate was decanted. After chicken serum diluted in assay buffer (100 $\mu \mathrm{l}, 1 \%)$ was added to each well, $15 \mu \mathrm{l}$ of GH standard (0.78 to $100 \mathrm{ng} / \mathrm{ml}$, NIDDK-bGH, AFP-9984C) dissolved in assay buffer or plasma was incubated in the wells for $24 \mathrm{~h}$. After decanting the plate, biotin-labeled GH was distributed into all the wells and then incubated for $3 \mathrm{~h}$. Finally, colorimetric treatments were carried out. The intraand interassay CVs were 8.1 and $8.5 \%$, respectively, and the ED50 of this assay system was $6.2 \mathrm{ng} / \mathrm{ml}$.

Determination of IGF-1 in plasma was performed by the EIA after protein extraction using an acidethanol $(87.5 \%$ ethanol and $12.5 \%$ 2N hydrochloric acid) to obtain IGF-1 free from the binding proteins [19]. Thirty $\mu$ of human IGF-1 standard (Roche, Indianapolis, IN, USA; 0.39 to $50 \mathrm{ng} / \mathrm{ml}$ ) dissolved in assay buffer or sample was added to each well coated with anti-rabbit $\gamma$-globulin antiserum. In addition, $100 \mu \mathrm{l}$ of biotin-labeled hIGF-1 $(\times 10,000)$ and rabbit anti-hIGF-1 ( $\times$ 40,000, NIDDK, AFP18111298) diluted in assay buffer were distributed into all the wells and then incubated for $72 \mathrm{~h}$ at $4 \mathrm{C}$. Finally, colorimetric treatments were carried out. The intra- and interassay CVs were 5.7 and 6.6\%, respectively, and the ED50 of this assay system was $2.5 \mathrm{ng} / \mathrm{ml}$.

Determination of insulin in plasma was carried out by EIA. Insulin standard (Sigma, St. Louis, MO, USA) was diluted with charcoal-treated serum (insulin-free). Thirty $\mu \mathrm{l}$ of insulin standard (39 to $5,000 \mathrm{pg} / \mathrm{ml}$ ) or plasma were added to each well coated with anti-guinea pig goat $\gamma$-globulin antiserum. In addition, $100 \mu \mathrm{l}$ of anti-bovine guinea pig insulin $(\times 150,000$, Dr. Schams) dissolved in assay buffer was distributed into all the wells and then incubated for $24 \mathrm{~h}$ at $4 \mathrm{C}$. After decanting the plates, $100 \mu$ l of biotin-labeled bovine insulin ( $\times$ $50,000)$ was distributed into all the wells and then incubated for $2 \mathrm{~h}$ at $4 \mathrm{C}$. Finally, colorimetric treatments were carried out. The intra- and interassay CVs were 9.7 and $14.5 \%$, respectively, and the ED50 of this assay system was $800 \mathrm{pg} / \mathrm{ml}$.

\section{Biochemical analyses}

In each sample, the concentration of glucose, NEFA, ketone body, T-cho, and AST were measured using a clinical chemistry automated analyzer (Hitachi 7250, Hitachi High-Technologies, Tokyo, Japan).

\section{Calculation of the ratio of increase in daily milk yield}

We calculated the linearity of the ratio of increase in daily milk yield from the onset of lactation to a significant increase in daily milk yield as follows. The ratio of increase in milk yield $=(\mathrm{MYs}-\mathrm{MYf}) / \mathrm{D}$, where $\mathrm{MYs}=$ milk yield on $\mathrm{D}, \mathrm{MYf}=$ milk yield on the $1^{\text {st }}$ day postpartum, and $\mathrm{D}=$ the day postpartum that the significant increase in dairy milk yield stopped.

\section{Statistical analyses}

All data were evaluated by repeated measures ANOVA. A significant interaction between group and time was observed in AST $(\mathrm{P}<0.01)$. Therefore, mean values were calculated for each cow for the sampling period, and the significant differences were analyzed by Student's t test. For other data, no significant interaction between group and time was observed. So, significant differences between ovulatory and anovulatory cows were analyzed using Student's $t$ test during the experimental period. In addition, when a significant effect of time was observed within a group, the change of factor in each group was analyzed using Fisher's least square difference test for BCS and BW or Tukey-Kramer test for other factors. Results were expressed as means \pm standard error of the mean (SEM). Differences of $\mathrm{P}<0.05$ were considered significant.

\section{Results}

The first ovulation and recovery of uterine size after parturition during the experimental period

In all cows, the first follicular wave postpartum was observed during the experimental period. The 
numbers of cows showing ovulation and anovulation of a dominant follicle during the first postpartum follicular wave were $6(37.5 \%)$ and 10 $(62.5 \%)$, respectively. The plasma concentrations of P4 in each group are shown in Fig. 1. The interval between calving and first ovulation was $17.2 \pm 1.2$ days in the ovulatory cows and $35.9 \pm 3.7$ days in the anovulatory cows $(\mathrm{P}<0.01$, Table 1$)$. The age of the cows and uterine involution did not differ between the two groups (Table 1).

Metabolites, metabolic hormones, and milk yields of the ovulatory and anovulatory cows during the experimental period

The significant increase in milk yield during the experimental period in the anovulatory and ovulatory cows stopped on 10 days postpartum and 13 days postpartum, respectively. The ratio of increase in milk yield in the anovulatory cows was

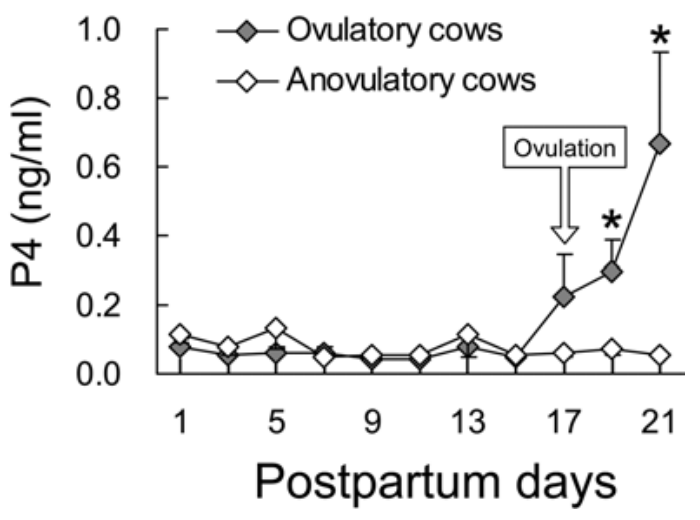

Fig. 1. The changes in plasma progesterone concentration in ovulatory $(n=6)$ and anovulatory $(n=10)$ cows during the experimental period (mean $\pm \mathrm{SEM})$. * Indicates differences of $\mathrm{P}<0.05$ between ovulatory and anovulatory cows. The day of ovulation was $17.2 \pm$ 1.2 days postpartum. higher than that in the ovulatory cows (1.907 \pm 0.186 vs. $1.208 \pm 0.154 \mathrm{~kg}$ /day, $\mathrm{P}<0.05)$. In addition, the daily milk yield during the experimental period in the anovulatory cows $(26.7 \pm 0.4 \mathrm{~kg} /$ day $)$ was higher than in the ovulatory cows $(22.7 \pm 0.5 \mathrm{~kg} /$ day, $\mathrm{P}<0.0001$, Table 1 ).

The plasma concentrations of glucose in the ovulatory cows were higher than in the anovulatory cows during the period of study $(\mathrm{P}<0.0001$, Fig. 2). The plasma concentrations of NEFA and ketone body in the anovulatory cows were higher than in the ovulatory cows during the experimental period ( $\mathrm{P}<0.0001$, Fig. 2). The plasma AST levels tended to be higher in the ovulatory cows on day 1 postpartum ( $\mathrm{P}=0.07)$, but tended to be higher in the anovulatory cows on day 11 postpartum ( $\mathrm{P}=0.09$, Fig. 2$)$. The plasma concentrations of T-cho were similar between the ovulatory and anovulatory cows during the period of study.

Figure 3 shows the change in metabolic hormones from day 1 to day 21 postpartum. The plasma concentrations of insulin and GH were not significantly different between the ovulatory and anovulatory cows during the experimental period. The plasma concentrations of IGF-1 in the ovulatory cows were higher than in the anovulatory cows during the period of study $(\mathrm{P}<0.001)$.

$B C S$ and $B W$ in the ovulatory and anovulatory cows at $-1,0$, and 1 week relative to parturition

There were no significant differences in BCS and BW between the ovulatory and anovulatory cows during the experimental period (Fig. 4). BCS and BW after parturition were lower than those before parturition in both the ovulatory and anovulatory cows $(\mathrm{P}<0.05)$. Moreover, the BCS and BW of the

Table 1. Ages, dates of first ovulation and recovery of uterine size after parturition, and milk yield of ovulatory and anovulatory cows at the first follicular wave postpartum

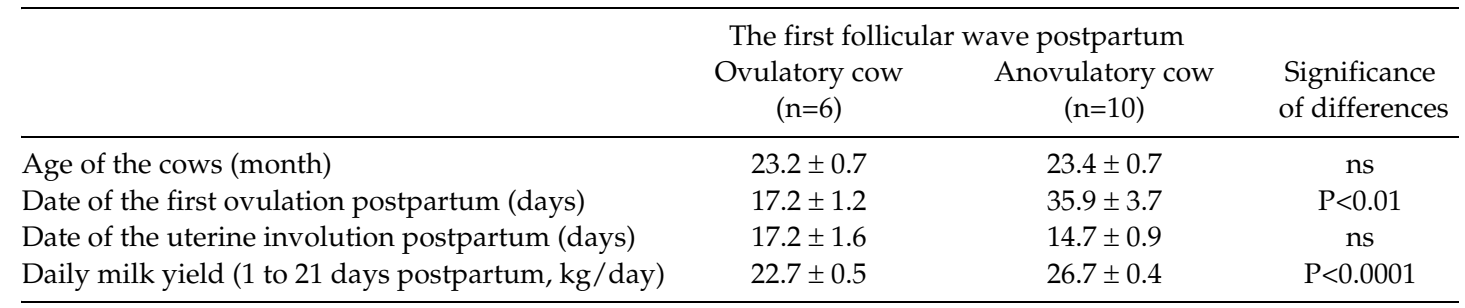

Values are means \pm SEM. ns: not significant. 

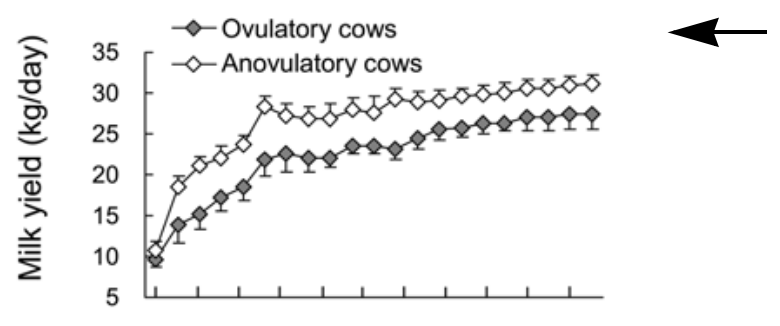

Fig. 2. Metabolites and milk yields from days 1 to 21 postpartum in ovulatory $(n=6)$ and anovulatory $(n=10)$ cows (mean \pm SEM). A significant interaction between group and time was observed in AST $(\mathrm{P}<0.01)$. No significant interaction between group and time was observed for other data. The plasma glucose $(\mathrm{P}<0.0001)$ concentrations were lower, and the plasma NEFA $(\mathrm{P}<0.0001)$, ketone bodies $(\mathrm{P}<0.0001)$, and daily milk yields $(\mathrm{P}<0.0001)$ were higher in the anovulatory cows during the experimental period compared with the ovulatory cows. The T-cho and AST levels did not differ between the two groups.
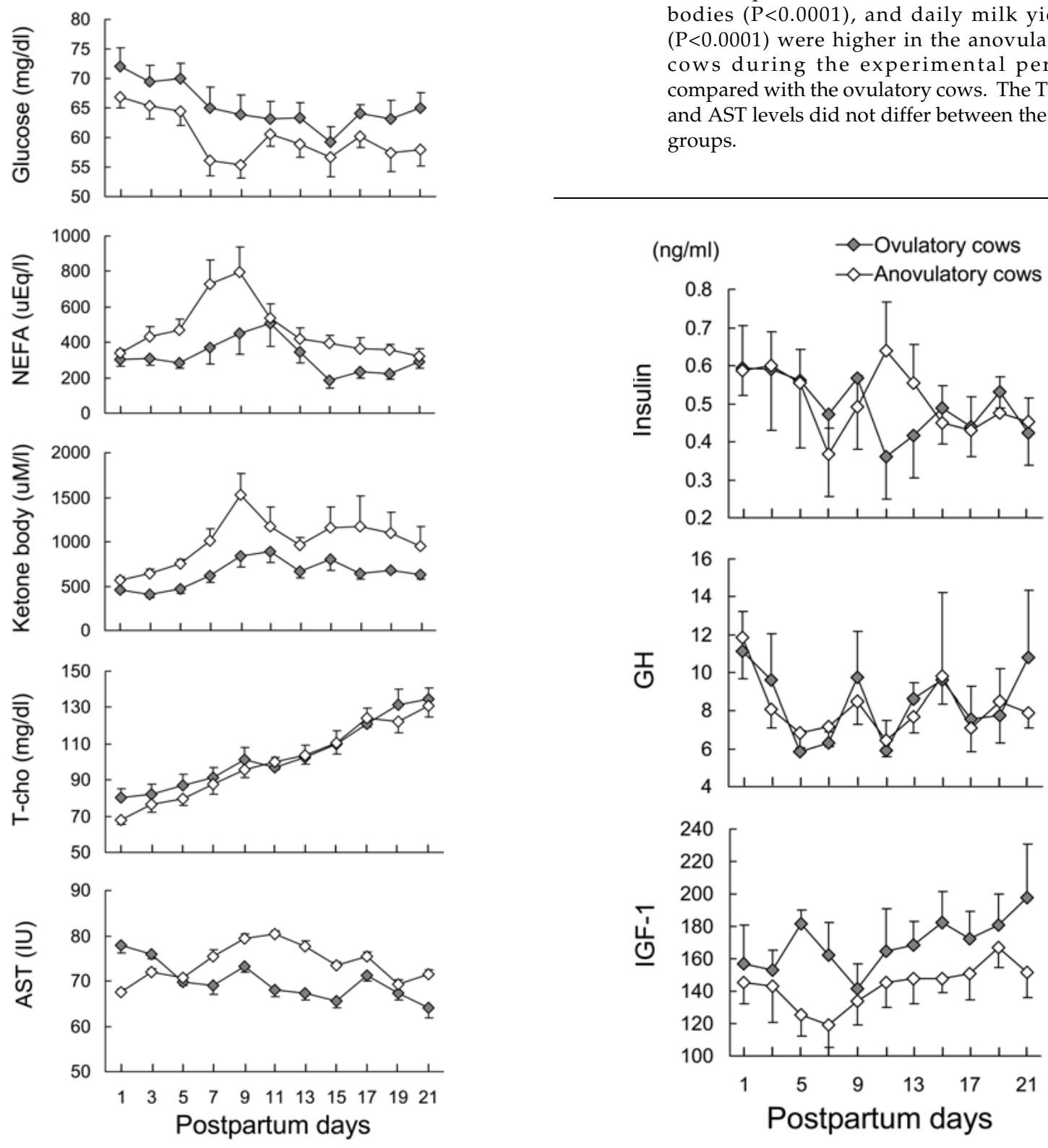

anovulatory cows 1 week postpartum were lower than during the week of parturition $(\mathrm{P}<0.05)$. On the other hand, there was no difference in the BCS and BW of the ovulatory cows between the week of parturition and 1 week postpartum.

Fig. 3. Metabolic hormones from days 1 to 21 postpartum in ovulatory $(n=6)$ and anovulatory $(n=10)$ cows (mean \pm SEM). The plasma IGF-1 $(\mathrm{P}<0.001)$ concentrations in the anovulatory cows were lower than in the ovulatory cows during the experimental period. The $\mathrm{GH}$ and insulin levels did not differ between the two groups. 

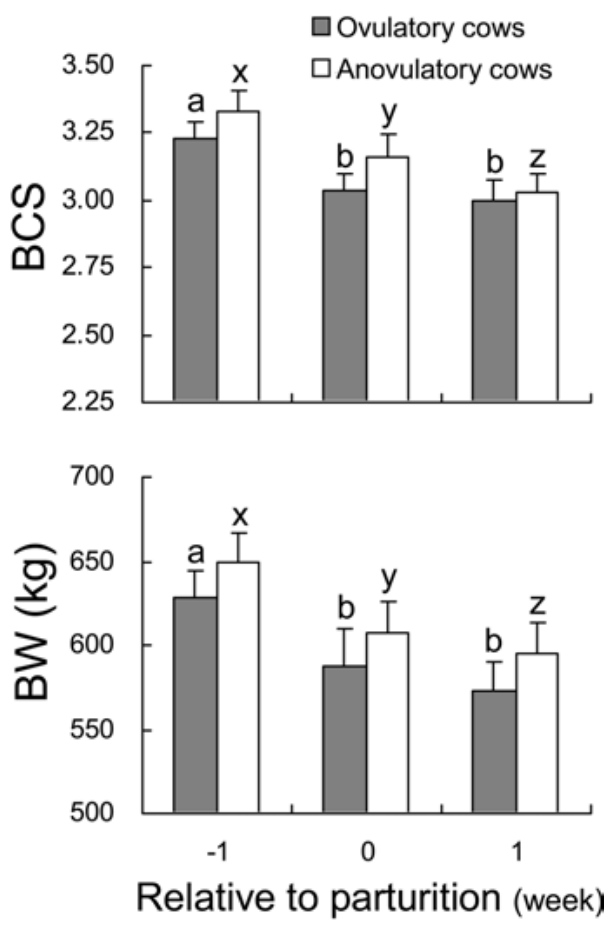

Fig. 4. BCS and BW at 1 week prepartum, on the day of parturition and 1 week postpartum in ovulatory $(n=6)$ and anovulatory $(n=10)$ cows (mean \pm SEM). $a$ and $b$ indicate differences of $\mathrm{P}<0.05$ within ovulatory cows. $\mathrm{x}, \mathrm{y}$ and $\mathrm{z}$ indicate differences of $\mathrm{P}<0.05$ within anovulatory cows. The BCS and BW levels did not differ between the two groups.

\section{Discussion}

The present study investigated the differences in the metabolic profiles and milk production in the ovulatory and anovulatory primiparous cows during the first follicular wave postpartum. The data indicates that the plasma IGF-1 levels were clearly related to the occurrence of ovulation at the first follicular wave postpartum. In addition, the plasma GH concentrations did not differ between the two groups, despite higher milk yields in the anovulatory cows compared with the ovulatory cows.

In the present study, the plasma concentrations of IGF-1 in the ovulatory cows were higher than in the anovulatory cows, and this is well consistent with previous studies using multiparous cows $[5,6$, 20]. IGF-1 stimulates estradiol production $[1,2]$ and the proliferation of follicular cells $[3,4]$. The present data also suggests that hepatic IGF-1 production is a direct influence that regulates the occurrence of ovulation of the dominant follicle during the first follicular wave postpartum in primiparous cows.

A decrease in the plasma IGF-1 concentration is induced by decline in the expression of $\mathrm{GH}$ receptor $1 \mathrm{~A}$ at parturition [21, 22], reducing negative feedback on GH $[22,23]$. Consequently, plasma GH concentrations are kept high after parturition, and these high GH levels can sustain milk production by promoting lipolysis in adipose tissue and ketogenesis in the liver $[24,25]$. The present study showed that the NEFA and ketone body concentrations of the anovulatory cows were higher than in the ovulatory cows. In addition, the BCS and BW of the anovulatory cows continued to decrease from 1 week prepartum to 1 week postpartum, whereas the decrease in these indexes in the ovulatory cows stopped at 1 week postpartum. This suggests that mobilization of body fat stores in the anovulatory cows was greater than in the ovulatory cows. Importantly, the ratio of increase in milk yield and the daily milk yields were higher in the anovulatory cows than in the ovulatory cows, but the plasma GH concentrations did not differ between the two groups. Thus, we hypothesize that the partitioning of nutrients induced by GH in anovulatory cows may be slightly different from ovulatory cows. That is, anovulatory cows likely promote more lipolysis for milk production than ovulatory cows, even if they have the same levels of $\mathrm{GH}$, and this may result in a more severe negative impact on liver function and follicular maturation. One peculiar property of primiparous cows is that they are still growing under the control of GH even after their first parturition and first onset of lactation. These particular physiological conditions may affect the complex of GH feedback and feedforward in the postpartum period [26]. Clearly, future studies are necessary to approach the relative contribution of GH secretion on growth and milk production in ovulatory and anovulatory primiparous cows during the first follicular wave postpartum.

The ratio of increase in milk yield was higher in the anovulatory cows than the ovulatory cows in this study. In the anovulatory cows, a significant increase in milk yield was synchronized with a decline in nutritional status, which was characterized by low glucose and IGF-1 
concentrations and high NEFA levels. In multiparous cows, the ratio of increase in milk yield until peak in anovulatory cows was higher compared with ovulatory cows (our unpublished data). Thus, the high ratio of increase in milk yield may be related to anovulation at the first follicular wave postpartum and may reflect the extent of the negative nutritional condition.

Overall, the present study suggests that anovulation of the dominant follicle during the first follicular wave postpartum in primiparous cows is induced by low IGF-1 levels, resembling the condition in multiparous cows.

\section{Acknowledgements}

The authors thank Dr. K. Okuda (Okayama University, Japan) for $\mathrm{P}_{4}$ antiserum, Dr. D. Schams (TU-Munich Weihenstephan, Germany) for insulin antiserum, and Dr. Parlow (NIDDK) for the GH standard, GH, and IGF-1 antiserum. This study was supported by a Grant-in-Aid for Scientific Research from the Japan Society for the Promotion of Science, the $21^{\text {st }}$ Century COE Program (A-1) of the Ministry of Education, Culture, Sports, Science and Technology of Japan, the Secure and Healthy Livestock Farming Project of the Ministry of Agriculture, Forestry and Fisheries, and the Japan Livestock Technology Association. C. Kawashima is supported by the COE Program.

\section{References}

1. Gutierrez CG, Campbell BK, Webb R. Development of a long-term bovine granulosa cell culture system: induction and maintenance of estradiol production, response to folliclestimulating hormone, and morphological characteristics. Biol Reprod 1997; 56: 608-616.

2. Glister C, Tannetta DS, Groome NP, Knight PG. Interactions between follicle-stimulating hormone and growth factors in modulating secretion of steroids and inhibin-related peptides by nonluteinized bovine granulosa cells. Biol Reprod 2001; 65: 1020-1028.

3. Spicer LJ, Alpizar E, Echternkamp SE. Effects of insulin, insulin-like growth factor I, and gonadotropins on bovine granulosa cell proliferation, progesterone production, estradiol production, and(or) insulin-like growth factor I production in vitro. J Anim Sci 1993; 71: 1232-1241.

4. Spicer LJ, Stewart RE. Interactions among basic fibroblast growth factor, epidermal growth factor, insulin, and insulin-like growth factor-I (IGF-I) on cell numbers and steroidogenesis of bovine thecal cells: role of IGF-I receptors. Biol Reprod 1996; 54: 255-263.

5. Beam SW, Butler WR. Energy balance, metabolic hormones, and early postpartum follicular development in dairy cows fed prilled lipid. J Dairy Sci 1998; 81: 121-131.

6. Kawashima C, Kaneko E, Amaya Montoya C, Matsui M, Shimizu T, Matsunaga N, Kida K, Miyake Y-I, Schams D, Miyamoto A. Relationship between metabolic hormones and ovulation of dominant follicle at the first follicular wave postpartum in dairy cows. In: Program of the $100^{\text {th }}$
Joint Annual Meeting of American Dairy Science Assosiation-American Society of Animal Science; 2006; Minneapolis, USA. Abstract 206.

7. Roche JF, Mackey D, Diskin MD. Reproductive management of postpartum cows. Anim Reprod Sci 2000; 60-61: 703-712.

8. Beam SW, Butler WR. Effects of energy balance on follicular development and first ovulation in postpartum dairy cows. J Reprod Fertil Suppl 1999; 54: 411-424.

9. Spicer LJ, Tucker WB, Adams GD. Insulin-like growth factor-I in dairy cows: relationships among energy balance, body condition, ovarian activity, and estrous behavior. J Dairy Sci 1990; 73: 929-937.

10. Lucy MC, Staples CR, Thatcher WW, Erickson PS, Cleale RM, Firkins JL, Clark JH, Murphy MR, Brodie BO. Influence of diet composition, dry matter intake, milk production and fertility in dairy cows. Anim Prod 1992; 54: 323-331.

11. Ronge H, Blum J, Clement C, Jans F, Leuenberger $\mathbf{H}$, Binder H. Somatomedin $\mathrm{C}$ in dairy cows related to energy and protein supply and to milk production. Anim Prod 1988; 47: 165-183.

12. Lucy MC. Reproductive loss in high-producing dairy cattle: where will it end? J Dairy Sci 2001; 84: 1277-1293.

13. Sakaguchi M, Suzuki T, Sasamoto $Y$, Takahashi $Y$, Nishiura A, Aoki M. Effects of first breeding age on the production and reproduction of Holstein heifers up to the third lactation. Anim Sci J 2005; 76: 419-426.

14. Kawashima C, Kaneko E, Amaya Montoya C, Matsui M, Yamagishi N, Matsunaga N, Ishii M, Kida K, Miyake Y-I, Miyamoto A. Relationship between the first ovulation within three weeks 
postpartum and subsequent ovarian cycles and fertility in high producing dairy cows. J Reprod Dev 2006; 52: 479-486.

15. Edmonson A, Lean J, Weaver LD, Farver T, Webster G. A body condition scoring chart for Holstein cows. J Dairy Sci 1989; 72: 68-78.

16. Sakaguchi M, Sasamoto Y, Suzuki T, Takahashi Y, Yamada Y. Postpartum ovarian follicular dynamics and estrous activity in lactating dairy cows. J Dairy Sci 2004; 87: 2114-2121.

17. Miyamoto A, Okuda K, Schweigert FJ, Schams D. Effects of basic fibroblast growth factor, transforming growth factor-beta and nerve growth factor on the secretory function of the bovine corpus luteum in vitro. J Endocrinol 1992; 135: 103-114.

18. Roh SG, Matsunaga N, Miyamoto A, Hidaka S, Hidari $\mathbf{H}$. Competitive enzyme immunoassay for bovine growth hormone. Endocr J 1997; 44: 195-198.

19. Daughaday WH, Mariz IK, Blethen SL. Inhibition of access of bound somatomedin to membrane receptor and immunobinding sites: a comparison of radioreceptor and radioimmunoassay of somatomedin in native and acid-ethanol-extracted serum. J Clin Endocrinol Metab 1980; 51: 781-788.

20. Beam SW, Butler WR. Energy balance and ovarian follicle development prior to the first ovulation postpartum in dairy cows receiving three levels of dietary fat. Biol Reprod 1997; 56: 133-142.
21. Kobayashi Y, Boyd CK, Bracken CJ, Lamberson WR, Keisler DH, Lucy MC. Reduced growth hormone receptor (GHR) messenger ribonucleic acid in liver of periparturient cattle is caused by a specific down-regulation of GHR $1 \mathrm{~A}$ that is associated with decreased insulin-like growth factor I. Endocrinology 1999; 140: 3947-3954.

22. Radcliff RP, McCormack BL, Crooker BA, Lucy MC. Plasma hormones and expression of growth hormone receptor and insulin-like growth factor-I mRNA in hepatic tissue of periparturient dairy cows. J Dairy Sci 2003; 86: 3920-3926.

23. Pushpakumara PG, Gardner NH, Reynolds CK, Beever DE, Wathes DC. Relationships between transition period diet, metabolic parameters and fertility in lactating dairy cows. Theriogenology 2003; 60: 1165-1185.

24. LeRoith D, Scavo L, Butler A. The somatomedin hypothesis. Endocr Rev 2001; 22: 53-74.

25. Lucy MC, McDougall S, Nation DP. The use of hormonal treatments to improve the reproductive performance of lactating dairy cows in feedlot or pasture-based management systems. Anim Reprod Sci 2004; 82-83: 495-512.

26. Giustina A, Veldhuis JD. Pathophysiology of the neuroregulation of growth hormone secretion in experimental animals and the human. Endocr Rev 1998; 19: 717-797. 